\title{
EL PERSONAJE HUMANO \\ COMO CREACIÓN AUTORAL AUTÓNOMA
}

\author{
Claudia Viascán CASTillo*
}

\section{INTRODUCCIÓN}

Quién no se ha sorprendido ante la amarga sensación de haber perdido a un ser querido cuando el personaje con el que ha convivido durante un periodo de tiempo, que puede ser largo pero también breve, y que ha dejado huella en él, deja de ser el que era para convertirse en otro por el hecho de cambiar el intérprete. No imagino sentarme a mirar la serie Doctor House sin el actor Hugh Laurie como intérprete del personaje, o detenerme a descansar con una comedia de Mr. Bean sin su creador e intérprete, Rowan Atkinson. Han sido diversas las ocasiones en que un actor brinda tal caracterización a un personaje que la persona de aquel se mimetiza con este, ocasionando en el público que los contempla una total confusión entre actor y personaje. Alrededor de esta situación cabe hacerse algunas preguntas pertinentes: ipueden los personajes constituirse en obras protegidas por el derecho de autor al ser expresiones originales de su autor?, ¿qué influencia ejerce la interpretación que hace un artista de un personaje y qué derechos se derivan en su favor de esa particular interpretación?, ¿se puede considerar que el intérprete del personaje, al dar vida a cada uno de los rasgos físicos y psicológicos de este, es quien hace del personaje una obra autónoma?, ¿es la interpretación una obra autónoma distinta del personaje?

Estas cuestiones son muy relevantes a los fines de establecer qué derechos tiene el autor del personaje, de qué derechos es titular el actor o intérprete del personaje, y qué derechos tiene el productor, quien finalmente es quien lleva adelante la puesta en escena de la obra, ya sea esta teatral, cinematográfica, coreográfica, televisiva,

* Abogada de la Escuela Libre de Derecho, México, D.F. Diplomada en Negocios Internacionales de la Escuela Libre de Derecho, México, D.F., y en Contratos del Instituto Tecnológico Autónomo de México, México, D.F. Especialista en Derechos de Autor por el Instituto de la Propiedad Intelectual y Derecho de la Competencia, México, D.F. Magíster en Propiedad Intelectual por la Universidad Austral, Buenos Aires, Argentina. Actualmente se dedica al libre ejercicio de la profesión. Fecha de recepción: 3 de marzo de 2016. Fecha de aceptación: 27 de julio de 2016. Contacto: [claudiaviascan@ hotmail.com]. Para citar el artículo: Viascán Castillo, C. El personaje humano como creación autoral autónoma. Revista La Propiedad Inmaterial n.o 21, Universidad Externado de Colombia, enero-junio 2016, pp. 25-45. DOI: DOI: http://dx.doi.org/10.18601/16571959.n21.02. 
historieta, animación, videojuego o cualquier otra. Pues es el productor, mediante la contratación de los autores e intérpretes, quien pone a disposición del público y de otros empresarios un proyecto que incluye a los personajes. Esa obra, a su vez, puede ser objeto de otras explotaciones, como el merchandising o comercios temáticos; o puede dar origen a secuelas, sagas u otro tipo de obras derivadas, incluyendo usos publicitarios del personaje. Toda esta pléyade de explotaciones tiene como centro a los personajes ${ }^{1}$.

El derecho de autor es el reconocimiento que hace el Estado en favor de todo autor respecto de sus obras, en virtud del cual otorga su protección para que este goce de prerrogativas y privilegios exclusivos de carácter personal y patrimonial ${ }^{2}$. En principio, toda obra es una creación intelectual original, que se protege sin valoración previa de sus cualidades, desde el momento de su creación; así, la protección la tiene un autor por el sólo hecho de ser creador de una obra. Al respecto, Luis Felipe Rangel Sánchez ha afirmado que "un creador se distingue por lo que inventa y no por lo que copia”.

Se considera obras a todas aquellas creaciones originales intelectuales expresadas en una forma reproducible ${ }^{4}$, luego un personaje original puede serlo. No obstante lo anterior, no es práctica en el derecho autoral reconocer expresamente

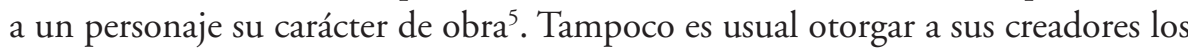
derechos que todo artista tiene por sus creaciones, derechos reconocidos inclusive como derechos humanos, como lo prevé la Declaración Universal de los Derechos Humanos al establecer en el artículo 27 que toda persona tiene derecho a la protección de los intereses morales y materiales que le correspondan por razón de las obras de su autoría ${ }^{6}$.

De lo anterior cabe concluir, y es materia de este ensayo justificar, que los personajes humanos de caracterización, siempre que reúnan las características de originalidad y expresión, deben ser considerados como obras; y las características específicas, ya sean, físicas, psicológicas, entre otras, son las que harán diferente a esta obra de otras y a un personaje de otro, siendo estos elementos los que permitirán que un personaje en particular sea materia de protección. Sin embargo, no basta

1. Yu, Peter. "Fictional Persona Test: Copyright Preemption in Human Audiovisual Characters”, Cardozo Law Review, vol. 20:355, 1998, p. 356.

2. Ley Federal del Derecho de Autor. Disponible en [www.indautor.gob.mx/documentos_normas/leyfederal], última visualización el 12 de marzo de 2016 . Referido en adelante COMO LFDA.

3. Rangel SÁnchez, Luis Felipe. "Interpretación, derechos de autor y derechos conexos", en Interpretación y autoría, Rogel, Carlos, coord., Colección de Propiedad Intelectual, Madrid, Fundación AIsGe 2004, p. 65.

4. ompi, Glosario de Derechos de Autor y Derechos Conexos, publicado por World Intellectual Property Organization, Ginebra, 1980. Referido en adelante como Glosario de la OMPI, p. 274.

5. Recordemos que la enumeración que hacen las leyes en materia autoral de las que deben considerarse obras es solamente ejemplificativa y no taxativa, pues es el ingenio humano que las provee y este no tiene límites.

6. Declaración Universal de Derechos Humanos. Disponible en [www.un.org/es/documents/udhr/], última visualización el 16 de mayo de 2014. 
decir que un personaje ha nacido en una obra, ya sea esta literaria, cinematográfica, teatral o cualquier otra. Podría darse que quien interpreta al personaje agregue originalidad con su actuación, y así este actor podría ser coautor del personaje interpretado o creador de una nueva obra.

Respecto de la originalidad el maestro ANTEQuera ha dicho: "Se ha sostenido en doctrina y también en sede judicial, que la originalidad se presume y quien la niega debe probarlo, de manera que la prueba de que la obra del actor no tiene ninguna originalidad incumbe a la parte demandada"7.

\section{El personaje}

... los personajes no pasaremos $[\ldots]$ porque nos dio la vida un autor.

Luigi Pirandello ${ }^{8}$

La creación de una obra obedece a la creatividad de una persona, quien de manera perceptible manifiesta una idea con características claras y definidas, que hacen del resultado una obra autónoma y materia de protección por el derecho autoral. Un personaje es una obra producto de la imaginación de una persona, en principio, el autor que crea un ser ficticio, imaginario, y en su caso, la obra de la que el personaje es parte; sin embargo, podría ser que el intérprete de aquel personaje, al impregnar de características propias al producto de la imaginación de otro, para dar vida a la obra, cree con su originalidad interpretativa un nuevo personaje.

Para definir qué es un personaje debemos decir qué es una persona. De acuerdo con el Diccionario de la lengua española, el término 'persona' viene del latín persõna, máscara de actor, personaje teatral, personalidad, persona, este del etrusco phersu, y este del griego $\pi \rho \square \sigma \omega \pi \mathrm{ov}$ (prósôpon). Y lo precisa como: "1. f. Individuo de la especie humana. 2. f. Hombre o mujer cuyo nombre se ignora o se omite [...] 5. f. Personaje que toma parte en la acción de una obra literaria. 6. f. Der. Sujeto de derecho. 7. f. Fil. Supuesto inteligente"

Esta misma obra señala que 'personificar' viene del término 'persona' y '-ficar', y lo define como: "1. tr. Atribuir vida o acciones o cualidades propias del ser racional al irracional, o a las cosas inanimadas, incorpóreas o abstractas. 2. tr. Encarnar de manera eminente una cualidad, una idea, etc. [...] 3. tr. Concretar en alguien la representación de un suceso, idea, etc." ${ }^{10}$.

7. Antequera Parilli, Ricardo. Estudios de Derechos de Autor y Derechos Afines, Colección de Propiedad Intelectual, Madrid, Fundación AISGE, 2007, p. 58.

8. Citado por Monner Sans, José María, El teatro de Pirandello, en Ottobre, Salvador "Pocho". Elogio del autor, Buenos Aires, La Crujía Ediciones, 2005, p. 41.

9. Real Academia Española. Diccionario de la lengua española. Disponible en [http:// dle.rae.es/?id=SjUIL8Zlema.rae.es/drae/?val=obra]. Última visualización el 11 marzo de 2016 , voz "persona".

10. Ibíd., voz "personificar". 
Asimismo, se define 'personaje' de la siguiente manera: "1. m. Persona de distinción, calidad o representación en la vida pública. 2. m. Cada uno de los seres humanos, sobrenaturales, simbólicos, etc., que intervienen en una obra literaria, teatral o cinematográfica" ${ }^{11}$.

También podríamos definir a los personajes en función de sus características. En la doctrina no encontramos una clasificación de los personajes, pero la legislación mexicana habla de personajes simbólicos, personajes ficticios y personajes humanos de caracterización. Bien podemos definir a los personajes simbólicos como creaciones intelectuales para la percepción de conceptos reales pero intangibles, por ejemplo, "la Primavera", "la Muerte"; los personajes ficticios son creaciones intelectuales de seres sobrenaturales, con características irreales o inexistentes: aquí estarían "Superman" y "Batman"; y personajes humanos de caracterización, que son creaciones intelectuales que representan mediante la caracterización en una persona situaciones reales, cotidianidades, por ejemplo, vivencias de un sector socioeconómico, emociones, sentimientos, anhelos, etc.

Desde la mirada de los intérpretes podemos distinguir dentro del último grupo tres tipos de personajes humanos de caracterización: 1) primero, aquellos que han sido creados por un autor en un proceso creativo dentro de otra obra, ya sea literaria, cinematográfica, de radio, televisión o cualquier otra. Son los personajes genéricos que reclaman del intérprete nada más que un simple análisis, un estudio y una comprensión de la obra (personaje) para ejecutarla; 2) luego, aquellos que han sido imaginados y realizados íntegramente por el autor, dotándolos de características particulares que los definen; 3) por último, aquellos personajes en los que la interpretación particular de un actor cobra una personalidad autónoma, donde tiene relevancia la astucia, la singularidad y la creatividad de quien los encarna. Son personajes producto de la imaginación y de la creación de una persona; sin embargo, quien ha llevado a cabo su ejecución haciendo accesible la obra al público es un actor que permite el conocimiento y la identidad de dichos personajes por parte de quien los percibe. En estos casos, parecería que dicha interpretación goza de un mérito diferente al del autor y al de la obra donde se inserta. Consideramos que sólo en este último supuesto los intérpretes de un personaje pueden ser tenidos en cuenta como partícipes en la creación, pues si los personajes han sido creados como obras autónomas y son diseñados y descritos en detalle por su autor, es poco lo que el actor puede aportar a dichas obras.

Tratándose de los actores y de los personajes humanos de caracterización que tienen esta singularidad, es decir, que permiten vislumbrar dos obras en un mismo acto, el personaje y la interpretación del personaje, encontramos diversos y muy ejemplificativos casos, como los personajes mexicanos del programa La Vecindad del Chavo, creados por Roberto Gómez Bolaños, en este caso en su calidad de autor-escritor, e interpretados por diversos actores, entre ellos (además del propio

11. Ibíd., voz "personaje”. 
Gómez Bolaños) la actriz María Antonieta Gómez Rodríguez, quien interpretaba a "La Chilindrina".

\section{ELEMENTOS DE PROTECCIÓN EN LOS PERSONAJES HUMANOS DE CARACTERIZACIÓN}

Un personaje debe estar protegido como una obra siempre que reúna los requisitos que para ser considerada como tal establezca la legislación correspondiente. La maestra Delia Lipszyc señala que el derecho de autor está destinado a proteger la forma representativa, la exteriorización de su desarrollo en obras concretas para ser reproducidas, representadas, ejecutadas, exhibidas, radiodifundidas, etc., según el género al cual pertenezcan ${ }^{12}$.

Tratándose del personaje humano de caracterización, la originalidad como requisito general se manifiesta en diversas características o rasgos del personaje, que se traducirán al ser correctamente expresados en elementos a proteger, por ejemplo: a) descripción física del personaje (fisonomía, voz, actitudes, ademanes, gestos, movimientos, mañas, tics, malestares, enfermedades, etc.); b) descripción psíquica (rasgos psicológicos, síndromes, miedos, manías, etc.); c) detalles de comportamiento (desenvolvimiento en privado, en público, en familia, en su entorno social, etc.); d) detalles de vida (entorno social) (formas de relacionarse, interactuar, comunicarse, etc.), entre otros. El detalle que haya puesto el autor de un personaje en estos elementos o características distinguirá la obra/personaje de cualquier otra, y reducirá las posibilidades de conflictos con otros autores de personajes similares o semejantes, o con el o los intérpretes de su obra, o con los productores de la obra $\mathrm{u}$ obras en que participe el personaje de que se trate.

\section{Autoría DEL PERSONAJE HUMANO DE CARACTERIZACIÓN}

El artista escoge en si numerosos gérmenes de vida hasta que uno o varios se injertan en su imaginación y conviértense en seres vivientes que siguen actuando por su cuenta.

Luigi Pirandello ${ }^{13}$

Autor es la persona que crea una obra ${ }^{14}$. CABALLERo define al autor como el individuo (persona natural) que ha creado una obra literaria o artística. Señala que por ser la

12. Lipszyc, Delia. Derecho de Autor y Derechos Conexos. Buenos Aires, unesco-CerlalcZavalía, 1993, p. 62.

13. Citado por Monner Sans, en Отtobre, Elogio del autor, cit., p. 41.

14. ompi, Glosario de la ompi, p. 23. El Diccionario de la lengua española lo define como la "persona que es causa de algo; persona que inventa algo; persona que ha hecho alguna obra científica, literaria o artística": ob. cit., voz "autor". 
obra de creación resultado de la exteriorización del pensamiento humano, el carácter de autor sólo puede atribuirse a una persona física, dado que es la única capaz de expresar emociones, de plasmarlas en diversas formas, lenguajes y soportes materiales $\mathrm{y}$ de divulgarlas a terceros mediante variadas formas y mecanismos ${ }^{15}$. En este sentido, todas las artes son formas de expresión creativa. Las personas pueden expresar su creatividad visualmente, mediante el movimiento, sonidos o la escritura, en tres dimensiones, vía multimedia, etc. Las expresiones artísticas se denominan obras ${ }^{16}$.

Una obra debe expresarse para existir, pues una obra en la mente de su autor sería sólo una idea y como tal no es susceptible de protección por el derecho de autor. La forma de expresión de una idea es la que definirá su carácter de obra y la que permitirá diferenciarla de cualquier otra. Conforme al Convenio de Berna, no importa cuál sea la forma de expresión de una idea para ser considerada una obra. Roberto IgARZA indica que "el autor construye primero para sí mismo y luego para los demás, pero es evidente que la sociedad le reconoce el rol de autor a quien comparte su creación"17.

LipszyC afirma que las obras deben tener la característica de ser reproducibles de cualquier forma para que puedan ser comunicadas y conocidas por el público. Es del derecho de autorizar o prohibir la reproducción de una obra, en cabeza de su autor, que se origina la figura de los intérpretes, los cuales, de alguna de las maneras permitidas por la ley, pondrán la obra en conocimiento del público que la percibe.

Quien crea una obra es reconocido por el derecho autoral como un autor. El esfuerzo creativo y la originalidad que implican crear una obra, cualquiera sea esta, merecen para su autor reconocimiento y protección. De esta manera, los autores de personajes deben tener los derechos que la legislación autoral otorga a cualquier otro creador, esto es, derechos morales y derechos patrimoniales. De acuerdo con el Convenio de Berna, los autores podrán autorizar, respecto de su obra: la representación y la ejecución públicas, por todos los medios o procedimientos; la transmisión pública por cualquier medio, de la representación y de la ejecución; toda comunicación pública y transmisión pública por cualquier medio; las adaptaciones, los arreglos y otras transformaciones, teniendo al respecto un derecho exclusivo ${ }^{18}$.

A nuestros ojos, la creación de un personaje humano de caracterización se debe a la impronta del autor, quien lo crea en su imaginación, moldeando aquello que ha descubierto dentro de sí. También puede obedecer, en algunos casos, a los aportes originales que con su interpretación haga un artista, intérprete o ejecutor de un personaje, esbozado previamente como idea por un autor.

15. Caballero Leal, José Luis. Derecho de autor para autores, México, Libros Sobre Libros, Fondo de Cultura Económica, Cerlalc, 2004, p. 1.

16. омрі, Aprender del pasado para crear el futuro: las creaciones artísticas y el derecho de autor. Disponible en [www.wipo.int/export/sites/www/freepublications/es/copyright/935/ wipo_pub_935], publicación de la OMPI, abril 2008, p. 7, última visualización 16 de mayo de 2014.

17. Entrevista a Roberto Igarza, en Оттовre, Elogio del autor, cit., p. 78.

18. Convenio de Berna para la Protección de las Obras Literarias y Artísticas (Acta de París, 1971), publicada por la Organización Mundial de la Propiedad Intelectual, Ginebra, 1998. Ver arts. 11,11 bis, 11 ter y 12. 
Tratándose de los personajes humanos de caracterización que deben ser interpretados por una persona para llegar al público, el autor que ha creado a este personaje lo deja en manos de un artista elegido por sus características propias como actor, para que represente este personaje ante el público, dándole vida. Desde este ángulo, el autor del personaje ve en el intérprete de su obra sólo eso: un actor que da vida al producto de su imaginación, resaltando fríamente que la tarea del intérprete consiste en permitir que el público perciba el fruto de su ingenio. Lo anterior no significa que se reste importancia al trabajo de un intérprete, pero deja claro que los únicos derechos que en su caso pueden derivar en su favor son los propios de la interpretación.

Sin embargo puede darse el caso de que el actor de la mano con el autor realice aportes que en el conjunto final resultan inescindibles, siendo en tal caso ambos creadores del personaje percibido por el público. En este sentido GAFFOGLIO apunta: "el supuesto de coautoría entre autor e intérprete atañe exclusivamente, cuando el autor ha solamente delineado las características del personaje, finalizando su intérprete la labor creadora, quien en este supuesto se convierte, asimismo, en autor del mismo"19.

También podríamos hablar de una obra derivada, cuando, una vez creada por el autor la obra original (literaria, cinematográfica, etc.), el artista intérprete otorga e impregna al personaje de características y elementos propios, haciendo del personaje original un nuevo personaje, distinto del creado por el autor de la obra original, es decir, dejando "vivo" al primer personaje y creando uno nuevo, contando para ello por supuesto con la autorización del creador original.

O puede tratarse de una obra en colaboración, cuando el personaje se crea entre un autor y un actor, teniendo una misma idea a desarrollar; así el creador de la obra original en la cual nace el personaje y el intérprete del mismo hacen de este "una obra".

Diferente de todo lo anterior es el caso del actor que interpreta un personaje y que al hacerlo resulta autor de una nueva obra creada a partir de un mero diseño de un personaje (un personaje sin detalles) hecho por el creador de una primera obra. Se trata de aquellos supuestos en los que para que el actor haga la interpretación del personaje, este se convierte en una extensión de su cuerpo, de su alma, aportando aquel elementos originales y reemplazando al personaje por una obra autónoma esencialmente original, distinta del personaje del cual nace. Se trataría pues de una obra nueva. A pesar de que nadie crea algo de la nada, esto no significa que la inspiración lleve a la copia o al plagio, o a hablar necesariamente de una obra derivada o de una obra realizada en coautoría.

No obstante mi postura de dejar en cabeza del autor del personaje todas las facultades y derechos que derivan de esa creación, hemos de preguntarnos: ¿̇se debe permitir que la interpretación de un personaje, que aporte elementos significativos, sea considerada como parte de la obra, como un elemento más de esta?, ¿es posible

19. Gaffoglio, Gisela L. Consideraciones acerca de los actores, intérpretes y personajes, Buenos Aires, La Ley Actualidad, 24/7/2007. 
que, de la interpretación del personaje que hace un artista, nazca una obra nueva, autónoma, distinta del personaje creado por el autor de la obra original?

$\mathrm{Al}$ respecto, EMERY, analizando la jurisprudencia argentina, cita a DE SANCTIS, quien afirma que cuando una interpretación es independiente de la obra interpretada, estamos dentro del derecho de autor y no del derecho de intérprete ${ }^{20}$. EMERY considera en torno al caso del personaje "Minguito", creado por Juan C. Chiappe e interpretado por Juan C. Altavista, que en una obra literaria o artística puede haber personajes que son la esencia de la historia y otros que por sus elementos sólo pueden ser calificados como elementos secundarios de dicha obra, siendo el intérprete quien dota a ese personaje de una vida propia, lo cual no constituye plagio de la obra original ${ }^{21}$.

Será cuestión de verificar en cada caso si, de hecho, el aporte del intérprete a la elaboración del autor agrega originalidad suficiente como para otorgarle coautoría ${ }^{22}$.

\section{El INTÉRPRETE}

La interpretación es, necesariamente, creadora, aporta algo que la obra literaria no contiene ni está, lógicamente, implícito en ella. Los sonidos y/o los gestos del artista (o provocados por él) nos traen una realidad sonora y/o visual nueva.

Carlos Rogel ${ }^{23}$

La acción de interpretar consiste en explicar o declarar el sentido de algo, y principalmente el de un texto; explicar acciones, dichos o sucesos que pueden ser entendidos de diferentes modos; concebir, ordenar o expresar de un modo personal la realidad; representar una obra teatral, cinematográfica, etc.; ejecutar una pieza

20. Emery, Miguel A. "La propiedad intelectual sobre personaje (El caso de "Minguito")". La Ley 1987-E. Fallo comentado: Cámara Nacional de Apelaciones en lo Civil, sala B (CNCiv) $($ SalaB $)$ - 1987/03/26 Reboiras de Chiappe, Hilda E. c. Altavista, Juan C. y otros.

21. En Warner Bros, Inc. v. CBS Inc. (216-F, 2d.945-9th Civ. 1954) el tribunal expresó: "Es concebible que el personaje constituya la esencia de la historia que se narra (en ese caso está comprendido dentro de la propiedad intelectual del autor). Pero si el personaje es sólo ‘el peón’ en el ‘juego de ajedrez' de narrar la historia, entonces no se encuentra dentro del área de protección conferida por el derecho de autor".

22. En palabras de Estévez Brasa, vocal propinante en la causa "Minguito": "Merece, pues, detenerse a considerar si el personaje 'Mingo', en cuanto a su forma de expresión, vestimenta, gestos, es un producto nacido de la propia calidad actoral de J.C. Altavista o si, en cambio, Altavista ha animado una composición determinada creada por Chiappe [...] Es obvio que, en tales circunstancias, funcionó el binomio Chiappe-Altavista, y si se ha entendido que el personaje 'Mingo' mereció la protección legal-autoral, habría de entenderse también que la observación de Chiappe de una suerte de submundo porteño plasmó ese tipo bien captado por Altavista, que no se agota en una indumentaria determinada, en formas precisas de lenguaje típico, ni tampoco en una noción muy particular de la ética o la honestidad, sino que todos esos factores alternativamente juntos o espaciados, están sugiriendo al personaje. Esta manifestación [...] permite adelantar que quien suscribe se inclina por entender que en autos se está ante una coautoría de un personaje determinado, que debido a esa confluencia de actor e intérprete deja entrever un sincretismo particular de dos personalidades que dan vida a esa otra ficción”. Cámara Nacional de Apelaciones en lo Civil, Sala B, Reboiras de C.H. vs. Altavista, Juan y otro, 26-3-1987.

23. Rogel, Carlos. Interpretación y Autoria, p. 13. 
musical mediante canto o instrumentos; ejecutar un baile con propósito artístico y siguiendo pautas coreográficas ${ }^{24}$.

En principio los personajes son obras que nacen para ponerse a disposición del espectador, lo cual puede hacerse a través de cualquier medio, pudiendo entonces el autor de una obra darle vida con ilustraciones, palabras, expresiones o movimientos corporales, mediante una narrativa que describa sus ideas, emociones, pensamientos, etc., todo lo anterior sin menoscabar los derechos de su titular.

Como hemos dicho, la creación del personaje obedece a la creatividad de su autor, a la originalidad de la persona que diseñó las características descriptivas y distintivas de esta obra. No obstante, en la práctica debemos reconocer el papel que juegan muchos de los intérpretes en la percepción que el público tiene de un personaje. Estos personajes tienen un sello de distintividad derivado de quien los interpreta, que en algunos casos va más allá del creador.

El artículo 3 de la Convención Internacional sobre la Protección de los Artistas Intérpretes o Ejecutantes, los Productores de Fonogramas y los Organismos de Radiodifusión, define a los artistas intérpretes o ejecutantes como todo actor, cantante, músico, bailarín u otra persona que represente un papel, cante, recite, declame, interprete o ejecute en cualquier forma una obra literaria o artística ${ }^{25}$. Los derechos de los artistas intérpretes son bien diferentes de los correspondientes a los autores. Estos básicamente consisten en permitir o prohibir su incorporación a fonogramas o videogramas o bien a recibir una remuneración adicional en caso de usos secundarios de las fijaciones de sus interpretaciones, por ejemplo en los supuestos de puesta a disposición, distribución o alquiler contenidos en los Tratados TOIEF/WPPT ${ }^{26}$.

En palabras de Ово́N, "el artista intérprete es el comunicador del producto intelectual estético creado por la fuente humana del mensaje (el autor), sin importar que esa comunicación la realice por medio de su voz y cuerpo o mediante un instrumento que transforme en sonido las notas de un pentagrama" ${ }^{27}$.

Por su parte, Arroyo Almaraz y Cedillo Mencía hablan de la comunicación entre el autor y el público, acción para la cual el actor es el vehículo. Consideran que una obra interpretada toma vida propia, que la identidad de algunas obras se la proporcionan los actores, distinguiendo entre la identidad del actor, quien da vida y emoción a lo que se halla en un papel escrito e interpreta lo creado, y la identidad del autor ${ }^{28}$.

24. Diccionario de la lengua, ob. cit., voz "interpretar".

25. Convención de Roma, 1961. Convención Internacional sobre la Protección de los Artistas Intérpretes o Ejecutantes, los Productores de Fonogramas y los Organismos de Radiodifusión, publicada por la Organización Mundial de la Propiedad Intelectual, Ginebra, 2001. En adelante denominada Convención de Roma.

26. Para un detallado estudio de los derechos de los intérpretes, cfr. Antequera Parilit, Estudios de Derecho de Autor y Derechos Afines, cit., pp. 209 y ss.

27. Ово́n León, J. Ramón. Derecho de los artistas intérpretes, actores, cantantes y músicos ejecutantes, México, Trillas, 1996, p. 105.

28. Arroyo Almaraz, Isidoro y Cedillo Mencía, Gregorio. "La protección de la creatividad de los artistas e intérpretes", Revista ICONO 14, Madrid, 2014, pp. 7 y 8. 
El origen de los derechos de los intérpretes -conocidos como derechos conexos-, además de la ejecución que llevan a cabo, son los contratos o convenios mediante los cuales los autores permiten la representación por parte de estos intérpretes, para que la obra pueda ser explotada y comunicada. Teniendo como base este derecho en cabeza del autor, es decir el de autorizar la reproducción de su obra, los autores pueden y deben celebrar contratos de licencia para señalar los límites de la autorización que se otorga. Mientras más claro sea el contrato de licencia, menor será el margen en el que el intérprete pueda moverse para variar la obra original.

SchmidT reflexiona respecto de los personajes de caracterización humana y apunta que estos necesitan de la persona real para existir; que el vínculo entre personaje y persona es indisoluble porque en esencia las cualidades del personaje se deben a la persona; y que en cuanto a los personajes ficticios cabe más la idea de desincorporación o desvinculación, y que casi la totalidad de estos tienen una vida independiente a la del autor que los interpreta, con lo cual no importa quién sea este, basta que respete el perfil físico y psicológico del personaje; el personaje está más atado a la obra que a la persona ${ }^{29}$.

Pensemos en los personajes que forman parte de una obra teatral, por ejemplo, El violinista en el tejado; otro tanto se puede decir de La Bella y la Bestia. A quienes vemos esas obras, ya en cine, ya en teatro, no nos importa quién es el intérprete de cada uno de estos personajes, puesto que es la obra en sí misma la que nos gusta o no, aun cuando algunos intérpretes puedan adaptarse mejor a la caracterización hecha por el autor. Pero, ¿qué hay de personajes como "Charles Chaplin", personaje creado e interpretado por Charles Spencer, o "Cantinflas", creado e interpretado por Mario Moreno? Son personajes que quien los piensa o los mira no lo hace sino en relación con la persona de esos actores, y con la muerte de quien los interpreta muere el personaje. Cuando vemos a un actor diferente de Charles Spencer que interpreta a "Charles Chaplin", de inmediato juzgamos de una mejor o peor imitación del "verdadero" "Chaplin", y nos olvidamos que se trata de una interpretación más del personaje creado.

Al tomar en examen la interpretación no podemos obviar el sinnúmero de posibilidades que se tienen para el nacimiento de una nueva obra, primigenia o derivada, dependiendo de la originalidad. En el primer caso se trata de una obra nueva, diferente de otra ya creada; en el segundo, la originalidad radica en la aportación que se haga a la obra preexistente. Así, en la medida que el autor del personaje deje delimitadas en su totalidad las características y rasgos del personaje materia de interpretación, o al menos, alcanzando en ello la mayor claridad y detalle posible, menor será la contingencia para este, pues el intérprete se limitará a actuar.

29. Schmidt, Luis. "Las Reservas de Derechos al uso exclusivo dentro del sistema mexicano de la Propiedad Intelectual", El Foro, Órgano de la Barra Mexicana, Colegio de Abogados, A.C., decimotercera época, tomo xvi, número 1, primer semestre 2003. Disponible en [www.olivares.com.mx/En/Knowledge/Articles/CopyrightArticles/LasReservasdeDerechosalusoexclusivodentrodelsistemamexivanodelaPropiedadIntelectual], numeral C.2.2. Última visualización 16 de mayo de 2014. 
Podríamos preguntarnos: ¿hay una colisión de derechos entre el autor del personaje y quien lo interpreta, en los casos en que quien personifica al personaje no es el mismo actor que lo crea? En principio, siguiendo la doctrina de la armonización de derechos, como la expone por ejemplo Toller, no se debe hablar de un conflicto de derechos, como tampoco considerar que hay una jerarquización entre ellos. De acuerdo a esta posición doctrinaria, no se puede utilizar una metodología que "sacrifica unos derechos en beneficio de otros" 30 . Hay una línea, en algunos casos muy delgada, para establecer los límites entre los derechos de quien crea un personaje y los de quien lo interpreta, siendo necesario conocer los elementos jurídicos y características de cada relación entre autor e intérprete, para afirmar en cabeza de quién quedan los derechos de la obra.

$\mathrm{Al}$ respecto GAFFOGLIO señala que "cuando un actor interpreta un personaje se fusionan alquímicamente el personaje creado por el autor y los elementos personales que le aporta el actor. El resultado de este proceso es una creación intelectual de titularidad del actor. Esta creación intelectual se denomina 'interpretación' y, en consecuencia, técnicamente el actor reviste el carácter de intérprete. La interpretación debe distinguirse del personaje interpretado, cuya titularidad corresponde - salvo en situaciones excepcionales- al autor que lo creó" ${ }^{31}$.

\section{Protección de personajes en la legislación autoral}

Dar protección a los personajes como obras autónomas no es práctica corriente en la comunidad internacional, o al menos no lo es por parte del derecho de autor. Se les ha protegido de otras formas, encuadrándolos en el concepto de obra, ya sea como obras de dibujo, obras gráficas, entre otras, o como diseños, o bajo el sistema de marcas, siempre y cuando cumplan con las características que para cada supuesto exige la legislación correspondiente.

La Copyright Act de Estados Unidos no contempla de modo expreso a los personajes dentro de la enumeración de objetos protegidos, lo que no significa que carezcan de protección, ya que la enumeración no es taxativa, al igual que ocurre en todas las legislaciones. Para gozar de la protección general deberán cumplir con los requisitos de cualquier obra, es decir, que se trate de la expresión original de una idea y que haya sido fijada en algún tipo de soporte ${ }^{32}$.

Así, resulta más sencillo determinar la originalidad cuando la expresión consta de elementos visuales, como en el caso de las historietas. Cuando la descripción es literaria, el personaje toma expresión en la mente del lector, y como estos pueden

30. Toller, Fernando. "Interpretación Constitucional. La resolución de los conflictos entre derechos fundamentales. Una metodología de interpretación constitucional alternativa a la jerarquización y el balancing test", en Interpretación Constitucional, Eduardo Ferrer Mac-Gregor (coord.), México, Porrúa, 2005, t. iI, pp. 1199-1284, en 1212.

31. Gaffoglio. "Consideraciones acerca de los actores", cit.

32. Howell, Dorothy. Intellectual Properties and the Protection of Fictional Characters. Copyright, Trademark or Unfair Competition?, Quorum Books, Westport, 1990, p. 86. 
ser muy diversos, los contornos son menos definidos. Esto no obsta para que una adecuada caracterización literaria manifieste originalidad suficiente. Si luego ese personaje es traspuesto al mundo visible y auditivo mediante la actuación, el dibujo o la animación, estaremos ante una particular obra derivada del personaje original ${ }^{33}$.

En Estados Unidos la discusión se presentó alrededor del derecho a la imagen o right of publicity del actor en su interpretación, frente al derecho de autor sobre el personaje que el productor ha recibido en cesión. Para determinar qué derechos conserva el actor y cuáles puede explotar el productor es necesario determinar el ámbito de validez de cada uno de estos derechos. En este sentido, se desarrolló el concepto de "fictional persona" frente al de "human persona" ${ }^{4}$. En este ensayo nos interesa el derecho de autor del personaje, por lo cual no pondremos mayor atención al derecho de imagen de los intérpretes.

La persona humana es aquella caracterizada por sus únicos atributos personales, como el nombre, la voz, la apariencia real, los modos de decir o moverse, entre otros. De algún modo todos los seres humanos tenemos esas características, más o menos destacadas o particulares, que son las que nos identifican y distinguen a unos de otros. Por el contrario, la persona ficticia o personaje es la persona abstracta, primero creada generalmente por un escritor o guionista primero en su imaginación y luego plasmada en algún modo de expresión que la hace comunicable y aprehensible por los demás. Como se puede deducir, las características personales del actor-intérprete y que constituyen su persona humana no pueden ser creadas por los autores ${ }^{35}$. En el fondo, es la misma idea que subyace en cuanto al derecho de autor que tiene el fotógrafo retratista y el derecho de la persona retratada, que no será - este último-del ámbito autoral sino que estará asociado a la intimidad, personalidad o privacidad, dependiendo del caso.

En cuanto a los personajes, la fijación en un soporte no corresponderá a la persona del actor en su interpretación, sino al medio que se haya utilizado para lograr la permanencia o comunicabilidad. Este podrá ser el celuloide, algún sistema de digitalización de imágenes, el papel o cualquier material bi o tridimensional. Pero no la persona del actor. Por el contrario, si la creación corresponde al actor, quien en la interpretación crea el personaje, a él pertenece la originalidad, siendo su persona -a su vez- el soporte primario de la creación.

Es decir que, si bien el propio significado de la palabra 'personaje' incluye a la creación en su misma naturaleza, en la legislación autoral no es práctica corriente reconocerle expresamente el carácter de obra. En el caso de los artistas es más correcto hablar de sus derechos como intérpretes o ejecutantes que como creadores.

33. La discusión sobre la protección de los personajes humanos de ficción renació con la aparición de los actores virtuales o digitales, quienes en algunas producciones reemplazaron a los actores de carne y hueso. Allí se volvió a argumentar respecto del nivel de creatividad que aporta la actuación, y si el actor que encarna al personaje puede tener derechos autorales. Cfr. Kurtz, Leslie. "Digital Actors and Copyright - From The Polar Express to Simone”, Santa Clara High Technology Law Journal, 21- 4, 2004, p. 802.

34. Cfr. Yu, ob. cit., p. 359.

35. Cfr. ibíd., pp. 375-377. 
La legislación mexicana prevé de manera indirecta la protección de los personajes como resultado de la fuente de la creatividad de su autor. No podemos hablar de una protección explícita pues se prevé, no su protección como una obra autónoma, sino sólo de algunos de sus elementos, bajo el cobijo de una figura jurídica con características propias: la "reserva de derechos al uso exclusivo"36. En principio, parecería que el legislador mexicano considera que los personajes son obras y como tal merecen protección. Sin embargo, es una protección parcial, pues se refiere al uso y explotación de las características de los diversos tipos de personajes que enumera, pero no hay disposición expresa que reconozca a los personajes como obras y a sus creadores como autores, con todos los derechos y prerrogativas que corresponden.

Con esta figura el legislador mexicano nos permite vislumbrar la idea de una obra existente, y recordemos que no hay obra si no hay autor. Tratándose de personajes, la LFDA prevé la protección de personajes ficticios, simbólicos y humanos de caracterización, creando la "reserva de derechos al uso exclusivo de características físicas y psicológicas de un personaje" ${ }^{37}$.

Para tales efectos, el Instituto Nacional del Derecho de Autor (INDAUTOR) define a los personajes que pueden ser materia de protección, como aquellos que cuenten con la originalidad y la caracterización que los haga únicos e inconfundibles ${ }^{38}$.

Respecto de los personajes, el artículo 173 LFDA define la figura de reserva de derechos como la facultad de usar y explotar en forma exclusiva características físicas y psicológicas distintivas de los personajes humanos de caracterización o ficticios o simbólicos. Se observa que hay un reconocimiento implícito a la existencia de una obra, respecto de la cual se otorga al titular la facultad exclusiva de usar y explotar, es decir, se otorga un derecho exclusivo, una facultad excluyente. El reconocimiento de la reserva de derechos, mediante la expedición del certificado correspondiente, será la fuente de los derechos y obligaciones que deriven para el autor del objeto de la reserva.

36. Jesús Parets ha afirmado: "estamos ante un nuevo y sui-géneris derecho que protege la vigente Ley Federal del Derecho de Autor y que no se relaciona propiamente con derechos de la creación, pero sí con la actividad creativa intelectual de otras figuras jurídicas que estaban relacionadas con los derechos de autor, pero que tienen tratamiento jurídico diferenciado". Y continúa: "el legislador quiso prever determinadas figuras que sin ser propiamente creaciones artísticas ni literarias originales, también gozaran de la tutela de los derechos de propiedad intelectual, por ser creaciones que tienen individualidad [...] estamos ante otras creaciones intelectuales protegidas como reservas de derechos, que el ordenamiento jurídico concede en favor de su titular un derecho exclusivo de explotación por el término que marca la legislación autoral, susceptible de renovación en tanto se acredite haberse usado tal cual, es decir, de la forma que fue solicitado su registro y en consecuencia otorgado”. Parets Gómez, Jesús. Teoría y práctica del Derecho de Autor, México, Sista, 2012, pp. 171 y 172.

37. La LFDA en el artículo 173 establece lo que es una reserva de derechos al decir: "es la facultad de usar y explotar en forma exclusiva títulos, nombres, denominaciones, características físicas y psicológicas distintivas, o características de operación originales aplicados, de acuerdo con su naturaleza, a alguno de los siguientes géneros: [...] III. Personajes humanos de caracterización, o ficticios o simbólicos”.

38. indAUTOR. "Anotación marginal para personajes humanos de caracterización, ficticios o simbólicos”. Disponible en [www.indautor.gob.mx/formatos/reservas/anotacion_personajes.html], última visualización: 12 de marzo de 2016. 
De acuerdo con la LFDA, la vigencia del certificado que expide INDAUTOR para las reservas de derechos para nombres y características físicas y psicológicas distintivas de personajes, tanto humanos de caracterización como ficticios o simbólicos, es de cinco años renovables, contados a partir de la fecha de su expedición. Para la renovación de la reserva se debe acreditar el uso de los elementos que fueron otorgados, que es sobre los cuales se da protección, es decir, se debe usar tal como se autoriza en el certificado.

\section{JURISPRUDENCIA RELEVANTE PARA}

\section{LA PROTECCIÓN AUTÓNOMA DE LOS PERSONAJES}

Es más frecuente la jurisprudencia referida a personajes ficticios de animación, pero resulta escasa la que involucra personajes humanos de caracterización. Probablemente esto se deba al incremento de las prácticas de merchandising generadas por los comics, películas de animación y tiras televisivas. El merchandising y su enorme impacto económico ha generado a su vez una intensa piratería, marco en el cual es recurrente que el infractor declame la falta de originalidad de los personajes protegidos ${ }^{39}$.

Algunos tribunales han resuelto en favor de la autoría y originalidad de los personajes, y por tanto de su protección. Así se resolvió en Argentina en un caso de denuncia de plagio, donde el autor introdujo personajes ficticios dentro de una novela histórica, los que fueron copiados por el plagiario bajo la excusa del "préstamo de personajes" 40 .

El modo de determinar el derecho a la protección de un personaje en particular es sacarlo de su contexto original y verificar su existencia autónoma.

A fin de establecer la originalidad de un personaje, la jurisprudencia norteamericana ha utilizado dos tests, que se pueden denominar "de la historia contada" y "del desarrollo", los cuales son útiles y podrían ser utilizados en otros sistemas jurídicos ${ }^{41}$. Así, se puede verificar que "Rambo" es reconocido por su protagonismo en

39. A modo de ejemplo, mencionamos el caso mexicano donde se reconoció la protección del personaje "Krusty El Payaso", creado por Matt Groening, dentro de la serie animada Los Simpson. Amparo directo 124/2013. Tiendas Tres B, S.A. de C.V. Primer Tribunal colegiado en materia administrativa del Primer Circuito. 05-9-2013. Para un caso español que se resolvió en sentido inverso, porque la copia no representaba el personaje "Piolín", de la Warner Bros Consumer Products, cfr. Recurso 8/2002, Sentencia 11/2002, Audiencia Provincial de Valencia, Sección 4. ${ }^{a}$, 24-1-2002. Ambos casos figuran en la reseña de jurisprudencia del CERLALC; ver: [www.cerlalc.org/derechoenlinea/dar/index.php].

40. Cfr. Ribak Marcos vs. Zicolillo Jorge Ignacio, Cámara Nacional de Apelaciones en lo Civil, Sala D, 14-11-2008, en el cual se reconoció que los personajes ficticios que el autor introduce dentro de la novela tienen una descripción, caracterización y roles que los hacen determinantes dentro del conjunto de la obra.

41. Cfr. Kurtz, ob. cit., p. 802. El test del desarrollo se focaliza en la distintividad del personaje, cuando los factores descriptivos tienen suficiente detalle para dotarlo de individualidad. El test de la historia contada hace referencia a lo imprescindible que resulte el personaje en una trama determinada. Bajo el primer criterio, "Sherlock Holmes" tendría suficiente protección, pero no así bajo el segundo, ya que es más relevante la trama, que podría desenvolverse con otro personaje. 
la saga de películas que lo ubican en un contexto selvático o agreste, representando la defensa del bien y la justicia, con un alto concepto de la lealtad y la amistad, por mencionar algunos aspectos. Pero si el mismo personaje es ubicado en una exploración interestelar, luchando contra alienígenas, y logramos distinguir que es el mismo "Rambo", podemos concluir que se trata de una creación autónoma, dotada de suficiente originalidad y expresión ${ }^{42}$. En definitiva, el personaje es una particular manifestación de la expresión de una idea.

La justicia de Estados Unidos, aplicando estos tests, resolvió que la caracterización del personaje "Rocky Balboa" era una de las mejor desarrolladas de la historia del cine norteamericano, en conjunto con su esposa "Adrian", su cuñado "Paulie" y su contrincante (luego entrenador) "Apollo Creed". Así, los personajes mismos en su desenvolvimiento y relaciones mutuas eran "la historia contada". El mismo tribunal, al analizar a "James Bond" a lo largo de las 16 películas diferentes, interpretadas a su vez por varios protagonistas, encontró que hay características comunes a todas esas interpretaciones, las que tienen que ver con la actividad propia de ese espía en particular ${ }^{43}$. De este modo, el personaje "James Bond" tiene suficientes aspectos originales para merecer protección autoral ${ }^{44}$.

Sin embargo, ninguno de estos casos jurisprudenciales toca a fondo la vinculación entre el personaje y los derechos de su autor en relación con los derechos del intérprete y la posible coautoría. A tal fin, vale la pena reseñar brevemente el caso del personaje llamado "La Chilindrina", ventilado dentro del particular marco de la legislación mexicana, que considera-como ya reseñé- la figura de la reserva de derechos al uso exclusivo. "La Chilindrina" es uno de los personajes del popular programa de televisión El Chavo del Ocho, creado y producido por Roberto Gómez Bolaños. El autor perdió la titularidad del personaje debido a la falta de renovación de la reserva de derechos. En efecto, María Antonieta de las Nieves, quien interpretó al famoso personaje, le disputó la autoría a Gómez Bolaños, resultando vencedora ${ }^{45}$.

En principio y conforme a los principios generales del derecho de autor, sólo el autor del personaje podría solicitar a la autoridad que se le otorgue dicho derecho, y en su caso, ser quien lo transmita a un tercero. Igualmente, él sería el titular de

42. Este ejemplo es una adaptación del que presenta Howell, ob. cit., p. 85 .

43. Cfr. Kurtz, ob. cit., pp. 803-804.

44. Metro-Goldwyn-Mayer v. American Honda Motor Co., 900 F. Supp. 1287 (C.D. Cal. 1995). En palabras del tribunal: "Reviewing the evidence and arguments, the Court believes that James Bond is more like Rocky than Sam Spade - in essence, that James Bond is a copyrightable character under either the Sam Spade 'story being told test' or the Second Circuit's 'character delineation' test. Like Rocky, Sherlock Holmes, Tarzan, and Superman, James Bond has certain character traits that have been developed over time through the sixteen films in which he appears. Contrary to Defendants' assertions, because many actors can play Bond is a testament to the fact that Bond is a unique character whose specific qualities remain constant despite the change in actors".

45. Cfr. Archivos del indautor. Agradezco al licenciado Marco Antonio Morales Montes y a todo su equipo su valiosa y desinteresada colaboración en la investigación de este trabajo. Gómez Bolaños, Roberto vs. Director General del Instituto Nacional del Derecho de Autor. Tribunal Federal de Justicia Fiscal y Administrativa, Sala Especializada en materia de Propiedad Intelectual. 11-8-2011. 
las acciones de nulidad y cancelación cuando se viere afectado en sus derechos por el otorgamiento de una reserva en contravención a lo anterior. Sin embargo, en la práctica no siempre resulta así. La legislación autoral mexicana no exige en ningún precepto que quien quiera solicitar una reserva de derechos al uso exclusivo de las características físicas y psicológicas de un personaje acredite de alguna manera ser el autor de la obra sobre la cual recae esta reserva, lo cual da lugar a situaciones como la que enfrentó Gómez Bolaños.

Podemos decir que en México, al menos de una manera parcial, se reconoce la impronta del autor en el personaje y sin calificarlo como obra se conceden, mediante el otorgamiento de una reserva de derechos, facultades de uso y explotación respecto de las características físicas y psicológicas de dicho personaje, pero no sólo a su autor, sino a cualquier tercero que lo solicite y cumpla con los requisitos que para dicho trámite establece la legislación autoral, con lo cual este esfuerzo legislativo se ve soslayado en demérito de los autores de personajes.

En este sentido, Contreras ha señalado:

Ante la existencia de los derechos que de manera expresa prevé la Constitución Política de los Estados Unidos Mexicanos, resulta un hecho incontrovertible que el Estado mexicano: [...] 4. Deberá privilegiar al autor de una obra, artística o literaria, sobre el derecho que supone el Registro que se otorga mediante una Reserva de Derechos al Uso Exclusivo. [...] 8. Lo que una Reserva de Derechos al Uso Exclusivo supone y lo que de su propia naturaleza se desprende es el derecho de autor. [...] 10. Se deberá aplicar la ley autoral en beneficio del autor y nunca privilegiar aquellas conductas que tengan como fin obtener un beneficio propio por medio de la titularidad de una Reserva de Derechos al Uso Exclusivo cuando se encuentre en pugna frente a un Derecho de Autor ${ }^{46}$.

Lo anterior debiera ser tenido en cuenta por la autoridad correspondiente para conceder o negar una reserva, pues la regulación de esta figura jurídica abre la puerta a que el creador de un personaje se quede sin la retribución correspondiente por la contribución que hace al acervo cultural de su país, o en su caso, se vea impedido de gozar de los derechos y prerrogativas que por dicha creación le corresponden. Se da paso con ello a una competencia desleal por parte de estos terceros que, mediante actos contrarios a los usos honestos, se aprovechan del esfuerzo o reputación ajena para beneficiarse: un verdadero enriquecimiento sin causa. Esto no sucedería si se le reconoce al personaje de manera explícita el carácter de obra y se le otorga la debida protección, pues como he señalado, el otorgamiento de una reserva al uso exclusivo presume la existencia previa de una obra respecto de la cual se concede ese uso.

46. Contreras Lamadrid, Cuauhtémoc Hugo. "El derecho de autor como derecho humano frente a las reservas de derechos al uso exclusivo". Derecho sin fronteras, Lerni Instrui, año 1, n.o 2, enero-junio de 2013, pp. 132 y 133. 
En principio, el derecho de autor del creador de un personaje es, si no jerárquicamente superior, por lo menos de mayor importancia frente al derecho de propiedad intelectual -reserva de derechos al uso exclusivo- del tercero distinto al autor que goza de una reserva de derechos de uso de las características del personaje creado por otro. Esto, por la simple razón de que el derecho del segundo no tendría lugar -de hecho no hubiera nacido- si el primero no hubiera creado el personaje. Asimismo, respecto a los posibles derechos del intérprete del personaje, obra respecto de la cual el intérprete ha podido crear su obra (la interpretación), ОвóN señala que el criterio adoptado tanto por la doctrina como por las legislaciones extranjeras establece la jerarquización del derecho de autor sobre los derechos de los artistas intérpretes ${ }^{47}$.

Todo lo anterior da lugar a otros interrogantes respecto del uso de personajes: ¿hay plagio por parte del intérprete al usar y explotar como propio, sin autorización por parte del autor, el personaje interpretado $?^{48}$, ¿hay infracción a los derechos de autor de los autores de personajes cuando los intérpretes de los mismos explotan en sus funciones, ya sea de circo, teatrales o cualquier otra, la descripción, los diálogos, los gestos creados por esos autores para sus personajes, sin contar para ello con la autorización correspondiente?

Algunas de estas preguntas encuentran respuestas en la doctrina y la jurisprudencia; por ejemplo, en la resolución dictada por la Cámara Nacional de Apelaciones en lo Civil, sala B, de la República Argentina, en el caso Reboiras de Chiappe, Hilda E. vs. Altavista, Juan C. y otros, que en términos generales resuelve que si de la interpretación que hace un actor resulta una obra diferente de la creada por el autor del personaje, por darle elementos distintivos y originales al mismo, no hay plagio por parte de este intérprete, pues el personaje que se interpreta carece de originalidad, la que le es dada por el actor, y que dicha interpretación es una nueva obra.

Incluso en la misma jurisprudencia mexicana se ha resuelto con posterioridad que el certificado de la reserva de derechos al uso exclusivo de un personaje de ficción no es autónomo de la obra de la que forma parte, ya que de lo contrario "se atentaría contra la unidad que conforman los elementos de una obra que, considerada como un todo o en sus partes, está protegida sin necesidad de inscripción

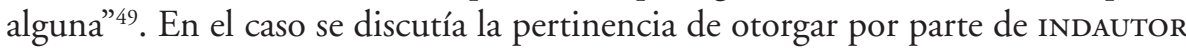
una reserva de derechos al uso exclusivo respecto del personaje ficticio llamado "Krusty El Payaso", personaje creado por Matt Groening dentro de la famosa

47. Овón León, ob. cit., p. 61.

48. En diversas entrevistas en las que se ha cuestionado a María Antonieta de las Nieves respecto del personaje "La Chilindrina", ha alardeado y se ha ufanado diciendo que "La Chilindrina es mía".

49. Primer Tribunal Colegiado en Materia Administrativa del Primer Circuito. Amparo directo 124/2013. Tiendas Tres B, S.A. de C.V. 5 de septiembre de 2013. Unanimidad de votos. Ponente: Julio Humberto Hernández Fonseca. Secretario: Luis Felipe Hernández Becerril. Tribunales Colegiados de Circuito. Décima Época. Gaceta del Semanario Judicial de la Federación. Libro 1, diciembre de 2013, p. 1105. 
serie de caricaturas norteamericana Los Simpson. En conclusión del tribunal, el personaje de "Krusty El Payaso" era notoriamente conocido en México, por lo cual se decidió, de manera correcta a mi parecer, que "debe entenderse que, en ese supuesto, el certificado únicamente tiene como finalidad otorgar una protección adicional y no autónoma de aquella que ya les provee el derecho autoral para la explotación de un personaje que hubiera adquirido mayor relevancia, pero sin ser desvinculado de la obra" ${ }^{50}$.

\section{Conclusiones}

Primera. El concepto de obra no puede corresponder a una clasificación numerus clausus ni taxativa. La enumeración que hacen las legislaciones en esta materia es ejemplificativa, por lo que cualquier creación original que quepa dentro de dichas categorías es una obra, incluyendo los personajes.

Segunda. La propiedad intelectual del personaje nace en el autor desde el momento de su creación, sin importar el mérito de la obra y sin exigirse para ello ninguna formalidad.

Tercera. Un personaje con características y elementos originales que permitan vislumbrar la impronta de quien lo crea, cuya expresión permita calificarlo como una obra así reconocida por la legislación autoral, debe ser protegido como tal, quedando en cabeza de su creador los derechos y prerrogativas que un Estado reconoce en cualquier autor por sus creaciones.

Cuarta. Para el caso de la legislación mexicana, la figura de la reserva de derechos al uso exclusivo de las características físicas y psicológicas de un personaje debe ser solamente un ejemplo de las formas que tiene el titular de una obra para conceder a un tercero el uso de su obra. Esta figura no tendría lugar si no existieran la obra y el autor de dicha obra, que es en todo caso quien estaría facultado para otorgar el derecho que por esta se concede. La regulación que ha hecho el legislador mexicano es incompleta y da lugar a que terceros, ajenos al acto de creación de la obra en uso, puedan hacerse a derechos que corresponden al autor de la obra y que sólo deberían poder tener con autorización por parte de este. El otorgamiento de una reserva de derechos al uso exclusivo de las características de un personaje debe tener como requisito previo la autorización por parte del autor de dicho personaje para otorgar el registro.

Quinta. La interpretación de una obra es sólo un acto que permite al autor de la misma darla a conocer al público, pero en principio, salvo que la voluntad de las partes sea otra, dicha interpretación no genera derechos respecto de la obra en favor del intérprete. Los únicos derechos que en su caso puede tener son los que de dicha interpretación deriven, es decir derechos conexos.

50. Ibíd. 
Sexta. Los criterios de la jurisprudencia norteamericana, tanto los que distinguen entre "fictional persona" y "human persona" como los referidos a los tests "la historia contada" y "del desarrollo", son útiles para resolver problemas de originalidad, autoría y titularidad, así como la posible vinculación que tendrá el intérprete respecto del personaje y su autor.

\section{BibLIOGRAFÍA}

\section{Diccionarios, libros y revistas}

Antequera Parilli, Ricardo. Estudios de derechos de autor y derechos afines. Colección de Propiedad Intelectual, Fundación AISGE, Madrid, 2007.

Arroyo Almaraz, Isidoro y Cedillo Mencía, Gregorio, "La protección de la creatividad de los artistas e intérpretes", Revista ICONO, n. ${ }^{\circ} 14$, año 2 , volumen 1, Madrid, 2004. Disponible en [www.icono14.net/ojs/index.php/icono14/ article/view/451].

Caballero Leal, José Luis. Derecho de autor para autores, México, Libros sobre Libros, Fondo de Cultura Económica, cerlalc, 2004.

Contreras Lamadrid, Cuauhtémoc Hugo, "El derecho de autor como derecho humano frente a las reservas de derechos al uso exclusivo", Derecho sin fronteras, Lerni Instrui, año 1, n.o 2, enero-junio de 2013.

Emery, Miguel A. "La propiedad intelectual sobre personaje (El caso de 'Minguito')". La Ley 1987-E. Fallo comentado: Cámara Nacional de Apelaciones en lo Civil, sala B (cNciv) (SalaB) - 1987/03/26 - Reboiras de Chiappe, Hilda E. c. Altavista, Juan C. y otros.

Gaffoglio, Gisela L. "Consideraciones acerca de los actores, intérpretes y personajes”, La Ley Actualidad, Buenos Aires, 24/7/2007.

Howell, Dorothy. Intellectual Properties and the Protection of Fictional Characters. Copyright, Trademark or Unfair Competition?, Quorum Books, Westport, 1990. INDAUTOR, "Anotación marginal para personajes humanos de caracterización, ficticios o simbólicos". Disponible en [www.indautor.gob.mx/formatos/reservas/ anotacion_personajes.html].

Lipszyc, Delia. Derechos de Autor y Derechos Conexos, París, Bogotá, Buenos Aires, Ediciones Unesco, Cerlalc, Zavalia, 1993.

ompr. Glosario de Derechos de Autor y Derechos Conexos, Ginebra, 1980.

OMPI. "Aprender del pasado para crear el futuro: las creaciones artísticas y el derecho de autor". OMPI, abril de 2008, p. 7. Disponible en [www.wipo.int/export/ sites/www/freepublications/es/copyright/935/wipo_pub_935].

Овón León, J. Ramón. Derecho de los Artistas Intérpretes, actores, cantantes y músicos ejecutantes, México, Trillas, 1996.

Ottobre, Salvador "Pocho". Elogio del autor, Buenos Aires, La Crujía Ediciones, 2005. Parets Gómez, Jesús. Teoría y práctica del Derecho de Autor, México, Sista, 2012. 
Patiño Alvés, Beatriz. "Marca registrada que vulnera el derecho de autor sobre el personaje Popeye". (Comentario a la Sentencia del Tribunal Supremo de 7 de octubre de 2000). Actas de Derecho Industrial y Derechos de Autor, t. XxI, Universidad de Santiago de Compostela, Marcial Pons, 2001.

Rangel SÁnchez, Luis Felipe. "Interpretación, derechos de autor y derechos conexos", en Interpretación y autoría, Rogel, Carlos, coord., Colección de Propiedad Intelectual, Fundación AISGE, Madrid, 2004.

Rogel, Carlos. Interpretación y autoría, Colección de Propiedad Intelectual, Fundación AISGE, Madrid, 2004.

Schmidt, Luis. "Las reservas de derechos al uso exclusivo dentro del sistema mexicano de la Propiedad Intelectual”, El Foro, Órgano de la Barra Mexicana, Colegio de Abogados, A.C., 13. ${ }^{a}$ época, t. XvI, n.o 1, primer semestre, 2003. Disponible en [www.olivares.com.mx/En/Knowledge/Articles/CopyrightArticles/LasReservasdeDerechosalusoexclusivodentrodelsistemamexivanodelaPropiedadIntelectual].

Toller, Fernando. "Resolución de los conflictos entre derechos fundamentales, una metodología de interpretación constitucional alternativa a la Jerarquización y el Balancing Test", en Interpretación constitucional, t. II, Eduardo FerRer Mac-Gregor (coord.), México, Porrúa, 2005.

Yu, Peter. "Fictional Persona Test: Copyright Preemption in Human Audiovisual Characters", Cardozo Law Review, vol. 20:355, 1998.

\section{Legislación, tratados internacionales y documentos}

Ley Federal del Derecho de Autor, Diario Oficial de la Federación, 24 de diciembre de 1996.

Reglamento de la Ley Federal del Derecho de Autor, en Diario Oficial de la Federación, 22 de mayo de 1998.

Convenio de Berna para la Protección de las Obras Literarias y Artísticas (Acta de París, 1971), Ginebra, OMPI, 1998.

Convención de Roma, 1961. Convención Internacional sobre la Protección de los Artistas Intérpretes o Ejecutantes, los Productores de Fonogramas y los Organismos de Radiodifusión, Ginebra, OMPI, 2001.

\section{Jurisprudencia}

Gómez Bolaños, Roberto vs. Director General del Instituto Nacional del Derecho de Autor. Tribunal Federal de Justicia Fiscal y Administrativa, Sala Especializada en materia de Propiedad Intelectual. 11-8-2011. 
Reboiras de C.H. vs. Altavista, Juan y otro. Cámara Nacional de Apelaciones en lo Civil, Sala B. 26-3-1987.

Ribak Marcos vs. Zicolillo Jorge Ignacio, Cámara Nacional de Apelaciones en lo Civil, Sala D, 14-11-2008.

Tiendas Tres B, S.A. de C.V. 5 de septiembre de 2013. Primer Tribunal Colegiado en Materia Administrativa del Primer Circuito. Amparo directo 124/2013. Tribunales Colegiados de Circuito. Décima Época. Gaceta del Semanario Judicial de la Federación. Libro 1, Diciembre de 2013.

Warner Bros, Inc. v. Свs Inc. (216-F, 2d.945-9th Civ. 1954).

Warner Bros Consumer Products, cfr. Recurso 8/2002, Sentencia 11/2002, Audiencia Provincial de Valencia, Sección 4. a, 24-1-2002. Ambos casos figuran en la reseña de jurisprudencia del CERLALC, [/www.cerlalc.org/derechoenlinea/ dar/index.php]. 